\title{
BMJ Open Assessment of healthcare delivery in the early management of bacterial meningitis in UK young infants: an observational study
}

\author{
Ifeanyichukwu O Okike, ${ }^{1}$ Shamez N Ladhani, ${ }^{2,3}$ Mark Anthony, ${ }^{4}$ Nelly Ninis, ${ }^{5}$ \\ Paul T Heath ${ }^{1}$
}

To cite: Okike I0, Ladhani SN, Anthony M, et al. Assessment of healthcare delivery in the early management of bacterial meningitis in UK young infants: an observational study. BMJ Open 2017;7:e015700. doi:10.1136/ bmjopen-2016-015700

- Prepublication history and additional material are available. To view these files please visit the journal online (http://dx.doi org/10.1136/bmjopen-2016015700).

Received 28 December 2016 Revised 24 April 2017 Accepted 25 April 2017

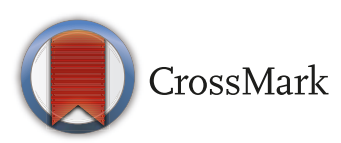

${ }^{1}$ Vaccine Institute and Institute for Infection and Immunity, St George's, University of London, London, UK

${ }^{2}$ Institute for Infection and Immunity, St George's, University of London, London, UK

${ }^{3}$ Immunisation, Hepatitis and Blood Safety Department, Public Health England Colindale, London, UK

${ }^{4}$ Neonatal Unit, John Radcliffe Hospital, Oxford, UK

${ }^{5}$ Department of Paediatrics, St Mary's Hospital, London, UK

Correspondence to Dr. Ifeanyichukwu 0 0kike; ifyokike@yahoo.com

\section{ABSTRACT}

Objective To define early presenting features of bacterial meningitis in young infants in England and to review the adequacy of individual case management as compared with relevant national guidelines and an expert panel review.

Design Retrospective medical case note review and parental recall using standardised questionnaires.

Setting England and Wales.

Participants Infants aged $<90$ days with bacterial meningitis diagnosed between July 2010 and July 2013. Results of the 97 cases recruited across England and Wales, 66 (68\%) were admitted from home and 31 $(32 \%)$ were in hospital prior to disease onset. Almost all symptoms reported by parents appeared at the onset of the illness, with very few new symptoms appearing subsequently. Overall, 20/66 (30\%) infants were assessed to have received inappropriate prehospital management. The median time from onset of first symptoms to first help was 5 hours (IQR: 2-12) and from triage to receipt of first antibiotic dose was 2.0 hours (IQR: 1.0-3.3), significantly shorter in infants with fever or seizures at presentation compared with those without (1.7 (IQR: 1.0-3.0) vs 4.2 (IQR: 1.8-6.3) hours, $p=0.02$ ). Overall, $26(39 \%)$ infants had a poor outcome in terms of death or neurological complication; seizures at presentation was the only significant independent risk factor $(\mathrm{OR}, 7.9 ; 95 \% \mathrm{Cl} 2.3$ to 207.0). For cases in hospital already, the median time from onset to first dose of antibiotics was 2.6 (IQR: 1.3-9.8) hours, and 12/31 (39\%) of infants had serious neurological sequelae at hospital discharge. Hearing test was not performed in $23 \%$ and when performed delayed by $\geq 4$ weeks in $41 \%$.

Conclusions In young infants, the non-specific features associated with bacterial meningitis appear to show no progression from onset to admission, whereas there were small but significant differences in the proportion of infants with more specific symptoms at hospital admission compared with at the onset of the illness, highlighting the difficulties in early recognition by parents and healthcare professionals alike. A substantial proportion of infants received inappropriate prehospital and posthospital management. We propose a targeted campaign for education and harmonisation of practice with evidencebased management algorithms.
Strengths and limitations of this study

- The strength of this study lies in the detailed analysis of a large cohort of geographically representative young infants with bacterial meningitis; this is the first study of its kind in the UK.

- We did not find any significant differences between the recruited and non-recruited cases in relation to age, sex, region of the country and causal bacteria (data not shown).

- Because we relied on paediatricians using their discretion to contact parents, however, this may have led to exclusion of families of infants who died or developed severe sequelae where the paediatrician was reluctant to contact the family about the study.

- Conversely, some parents may have agreed to participate simply because they were concerned about their child's long-term outlook or about suboptimal healthcare.

- Another potential limitation is that we relied on parents' recall for onset and progression of early clinical features. There is, however, evidence from other serious infections such as meningococcal disease that parents are able to accurately recall in detail such life-changing events.

\section{INTRODUCTION}

Bacterial meningitis in young infants remains a significant cause of mortality and long-term morbidity. ${ }^{1}$ During 2010-2011, we conducted national, prospective, population-based surveillance of bacterial meningitis in infants younger than 3 months of age in the UK and Ireland and found that $26 \%$ of 329 infants had poor outcomes at discharge. ${ }^{2}$ Among survivors of neonatal meningitis in the $1980 \mathrm{~s}$, $50 \%$ had neurological sequelae at 5 years of age, ${ }^{3}$ and similar rates $(40 \%)$ have been reported in survivors of neonatal bacterial meningitis in the $1990 \mathrm{~s}^{4}$.

The pathogens responsible for bacterial meningitis in young infants are different from those causing meningitis in other age 
groups, ${ }^{5}$ with group B streptococci and Escherichia coli responsible for more than half the cases; neither are currently vaccine-preventable. ${ }^{1}$

It is recognised that the early presentations of meningitis in young infants can be subtle and non-specific. This poses a substantial challenge for parents and healthcare workers. In our national surveillance, for example, half the infants with bacterial meningitis did not have fever at presentation and only $5 \%$ had the classic triad of fever, bulging fontanelle and seizures. ${ }^{2}$

Studies of invasive meningococcal disease have been able to delineate the onset of specific symptoms and signs and chart their progression over the course of the illness. ${ }^{6}$ This information has helped improve knowledge and increase awareness of meningococcal infections among parents and healthcare workers (http://www.meningitis.org/health-professionals/ doctors-in-training). Early recognition of meningococcal infection coupled with rapid antibiotic treatment and more aggressive management of children with sepsis has subsequently led to improved outcomes. ${ }^{7-9}$ In adults with sepsis, earlier antibiotics have been associated with higher survival rates, ${ }^{10}$ but in infants the evidence base is poor even though they have the highest incidence of bacterial meningitis. ${ }^{5}$

We hypothesised that earlier recognition may lead to earlier healthcare interventions, which in turn might improve the outcomes of bacterial meningitis in young infants. We, therefore, undertook a detailed assessment of the timing, course and progression of bacterial meningitis in young infants across England and Wales. We also compared their initial and subsequent clinical management with relevant national guidelines.

\section{METHODS}

We undertook a detailed review of the clinical presentation and management of bacterial meningitis in young infants in England and Wales diagnosed between July 2010 and July 2013 from the perspectives of parents and healthcare workers. We aimed to recruit 100 eligible infants (table 1) ${ }^{11-13}$ Cases were identified from LabBase2 (a national surveillance database used by National Health Service (NHS) hospitals laboratories to voluntarily, electronically report clinically significant infections to Public Health England). ${ }^{14}$

A study pack containing study details, a consent form and a questionnaire was sent to the local paediatrician to forward to parents. If families did not respond, we asked the paediatrician to send a second pack. Parents of all participants completed a questionnaire with details about onset and progression of specific symptoms. Participating parents also gave informed written consent for the study investigators to access their infants' medical records. All stages of care, including prehospital management, initial hospital assessment, ongoing care and postadmission follow-up, were assessed through an in-depth review of hospital notes.

\section{Assessment of management: expert panel and national guidelines}

An expert panel consisting of a general paediatrician, neonatologist, paediatric infectious diseases consultant and a paediatric specialist registrar reviewed the data to determine appropriateness of prehospital management, delays in recognition, empiric antibiotics, antibiotic duration and follow-up. These were judged according to any national guidelines available at the time. The National
Table 1 Definitions

Group Definition

Eligible infants

\section{Age at diagnosis}

Home admission Inpatients

Time from onset to first help

Time from onset to first dose of antibiotics

Time from triage to first dose of antibiotics

'In hours' (www.hscic.gov.uk)

Appropriateness
Infants $<90$ days of age in whom a bacterium was isolated from the cerebrospinal fluid (CSF), or where a significant bacterial pathogen was isolated from blood together with CSF pleocytosis (defined as $\geq 20$ cells $/ \mathrm{mm}^{3}$ for infants $0-28$ days of age and $\geq 10$ cells $/ \mathrm{mm}^{3}$ for infants $29-89$ days of age $)^{11-13}$

Early onset (0-6 days) and late onset (7-89 days) Infants admitted to hospital from home

Infants already in hospital at the time, either in the neonatal unit, birthing centre or postnatal ward

The time from when parents noticed the first clinical feature to the time they sought any type of help (phone call or visit)

The time from appearance of first clinical feature to first dose of antibiotics

The time from when infant was triaged by a nurse to the time of administration of the first dose of antibiotics

Triage in hospital between the hours of 09:00 and 18:00

Advice given prior to admission was judged as appropriate or inappropriate; choice of empiric antibiotics and duration of antibiotics were appropriate if in conformity with existing guidelines; for example, the use of any antibiotics other than amoxicillin and cefotaxime/ceftriaxone in any infant admitted from home would be classified as inappropriate 
Institute for Health and Care Excellence (NICE) feverish illness in children aged $<5$ years guideline ${ }^{15}$ was used to assess the appropriateness of advice/actions prior to hospital admission in febrile infants; in the absence of fever, the expert panel proposed a standard best practice. The Bacterial Meningitis and Meningococcal Septicaemia in Children guideline ${ }^{16}$ was used to assess the appropriateness of empiric antibiotics, length of treatment and timing of audiology testing for all cases. The management of infants presenting in the first 72 hours of life was assessed against the NICE antibiotics for earlyonset neonatal infection guideline. ${ }^{17}$ We adhered to the Strengthening the Reporting of Observational Studies in Epidemiology (STROBE) guidelines for reporting observational studies.

\section{Data collection}

Parents completed a questionnaire, which recorded the time of first appearance and progression of predefined clinical features. Information on any illnesses in the previous 2 weeks was also requested. Hospital medical notes and general practitioner (GP) letters in the medical notes were used to corroborate parental recollection of onset, timing and progression of events.

\section{Data analysis}

The data are mainly descriptive. We plotted the appearance and course of symptoms from the time of onset of first symptoms. The timing of each subsequent feature was then recorded and rounded to the nearest hour. For children admitted from home, we calculated the number of hours from the onset of illness to seeking any medical help ('first help'=hospital attendance, GP attendance or phone contact with a health professional) and to hospital admission. We compared the prevalence of symptoms at onset and at hospital presentation (infants admitted from home) or at diagnosis (inpatients). We also compared presenting features and clinical management in infants admitted from home and inpatients. Continuous data that did not follow a normal distribution are described as medians with IQRs and compared using the Mann-Whitney U or Kruskal-Wallis test, as appropriate. Proportions were compared using $\mathrm{X}^{2}$ or Fisher's exact test, as appropriate. To identify independent risk factors for poor outcomes (death or serious complications), potential explanatory factors were included in a backward, stepwise multivariable logistic regression model, and the least significant parameter was then sequentially removed until only those parameters with $\mathrm{p}<0.05$ remained.

\section{RESULTS}

A total of 224 infants with bacterial meningitis were identified and study information forwarded to the parents (figure 1). The parents of 103 infants $(46 \%)$ agreed to participate, but six cases were subsequently excluded because they did not meet the inclusion criteria. Demographic data on parents and infants are shown in

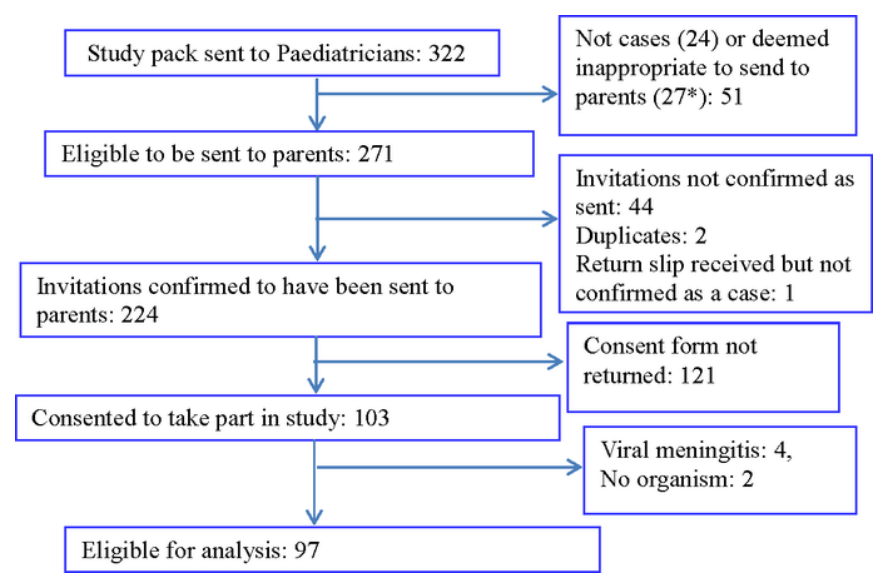

Figure 1 Recruitment algorithm ( ${ }^{*}$ died (8), moved away (5), foster care (2), language barrier (2)). Recruited cases were from $2010(n=25), 2011(n=39), 2012(n=22)$ and $2013(n=11)$.

table 2A,B. Cases were recruited from 48 hospitals representing all English regions (table 2B). Sixty-six (68\%) infants were at home when they became unwell and $31(32 \%)$ were inpatients. Most parents (92/97, 95\%) completed the study questionnaire. The median time (IQR) from diagnosis to return of questionnaire was 286 days (84-252).

\section{Cases admitted from home $(n=66)$}

The median age at diagnosis of bacterial meningitis was 14 days (IQR: 3-25), higher in cases admitted from home (17 (IQR: 11-34) days) compared with cases already in hospital (1 (IQR: 0-7) days; $\mathrm{p}=0.0001$ ). The most common features at onset of illness were poor feeding $(\mathrm{n}=44,65 \%)$, lethargy $(\mathrm{n}=30,45 \%)$ and fever (temperature $\left.\geq 38^{\circ} \mathrm{C}\right) \quad(\mathrm{n}=30,44 \%)$. The majority of symptoms reported by parents appeared at the onset of infection (figure 2A) and these symptoms persisted, with very few new symptoms appearing over the subsequent 24 hours (figure 2B). However, there were small but significant

\begin{tabular}{|c|c|c|}
\hline Parameter & Mother & Father \\
\hline Median parental age (IQR) & $29(26-33)$ & $32(26-36)$ \\
\hline \multicolumn{3}{|c|}{$\begin{array}{l}\text { Parents' highest academic level: } \\
\text { mothers }(n=79) \text {, fathers }(n=77)\end{array}$} \\
\hline Postgraduate & $16(20 \%)$ & 7 (9\%) \\
\hline Graduate & $16(20 \%)$ & $15(19 \%)$ \\
\hline A levels & $20(25 \%)$ & $13(17 \%)$ \\
\hline (GCSEs) & 27 (34\%) & 42 (55\%) \\
\hline \multicolumn{3}{|c|}{$\begin{array}{l}\text { Parents' accommodation: } \\
\text { mothers ( } n=87) \text {, fathers }(n=77)\end{array}$} \\
\hline Own house/flat & $45(52 \%)$ & $45(58 \%)$ \\
\hline Rented house/flat & 35 (40\%) & 26 (34\%) \\
\hline Council house/flat & $7(8 \%)$ & $6(8 \%)$ \\
\hline
\end{tabular}

GCSEs, General Certificate of Secondary Education; PICU, paediatric intensive care unit. 
Table 2B Basic demographics of all infants

\begin{tabular}{ll}
\hline Parameter & Value \\
\hline Male & $52(54 \%)$ \\
\hline Term ( $\geq 37$ weeks) & $74(76 \%)$ \\
\hline Preterm (<37 weeks) & $23(24 \%)$ \\
\hline $32-36$ & $14(14 \%)$ \\
$28-31$ & $5(5 \%)$ \\
$<28$ & $4(4 \%)$ \\
\hline Birth order & \\
Singleton & $88(91 \%)$ \\
Twins & $9(9 \%)$ \\
\hline
\end{tabular}

Age distribution

$\begin{array}{ll}\text { Early onset: } 0-6 \text { days } & 30(31 \%) \\ \text { Late onset: } 7-28 \text { days } & 44(45 \%) \\ 29-89 \text { days } & 23(24 \%)\end{array}$

Route of admission

\begin{tabular}{|c|c|}
\hline Home & $66(68 \%)$ \\
\hline Inpatient & $31(32 \%)$ \\
\hline \multicolumn{2}{|l|}{ Ethnicity } \\
\hline White & $81(84 \%)$ \\
\hline Asian & $6(6 \%)$ \\
\hline Black & $4(4 \%)$ \\
\hline Unknown & $6(6 \%)$ \\
\hline \multicolumn{2}{|l|}{ Region of England } \\
\hline North of England & $26(26 \%)$ \\
\hline Midlands and East of England & $18(19 \%)$ \\
\hline London and integrated regions & $13(13 \%)$ \\
\hline South of England & $39(41 \%)$ \\
\hline \multicolumn{2}{|l|}{ Infants mode of feeding at diagnosis } \\
\hline Breast feeding & $32(38 \%)$ \\
\hline Mixed feeding & $13(20 \%)$ \\
\hline Bottle feeding & $32(33 \%)$ \\
\hline \multicolumn{2}{|l|}{ Bacteria } \\
\hline Identified from Cerebrospinal fluid only & $23(24 \%)$ \\
\hline Identified from cerebrospinal fluid and blood & $40(41 \%)$ \\
\hline Identified from blood only & $34(35 \%)$ \\
\hline Group B streptococci & $65(63 \%)$ \\
\hline Escherichia coli & $11(11 \%)$ \\
\hline Listeria monocytogenes & $4(4 \%)$ \\
\hline Neisseria meningitidis & $4(4 \%)$ \\
\hline Other Gram-negative bacteria* & $10(10 \%)$ \\
\hline Other Gram-positive bacteria† & $5(5 \%)$ \\
\hline Alive & 96 \\
\hline $\begin{array}{l}\text { Dead (after } 28 \text { hours in PICU after developing } \\
\text { meningitis in the } 4 \text { th week of life) }\end{array}$ & 1 \\
\hline
\end{tabular}

*Pseudomonas spp 3, Klebsiella spp 2, Salmonella spp 2, Citrobacter 1, Pasteurella spp 1, Haemophilus influenzae 1. †Streptococcus pneumoniae 2, Streptococcus bovis 2 and $\alpha$-haemolytic streptococcus 1. differences in the proportion of infants with more specific symptoms at hospital admission compared with the onset of the illness: irritability $(\mathrm{p}=0.036)$, abnormal breathing $(\mathrm{p}=0.023)$ and abnormal movement/seizures $(\mathrm{p}=0.024)$ (figure 2C).

Twenty parents $(30 \%)$ took their infants straight to the hospital: the Accident and Emergency (A\&E) department $(\mathrm{n}=15,22.5 \%)$ or the urgent care centre $(\mathrm{n}=5,7.5 \%)$. The other parents $(\mathrm{n}=46,70 \%)$ sought help by phoning the GP $(n=21,32 \%)$, calling the 24-hour NHS direct telephone service $(\mathrm{n}=15,23 \%)$ or contacting the community midwife $(n=10,15 \%)$; of these, $13(28 \%)$ were advised to stay at home.

The median time from onset of first features to first help was 5.0 hours (IQR: 2.0-12.0). The time to first help was not associated with early-onset or late-onset disease, gestation at birth, presence of fever or seizure, region of the country, type of housing or level of maternal academic qualifications. The majority of parents $(47 / 62,76 \%)$ presented to hospital within 24 hours of onset of symptoms. Thirteen of $15(93 \%)$ infants who were presented after 24 hours had fever $(n=8)$ or seizures $(n=4)$ or both $(n=1)$ at the time they presented to hospital. Eight of the 15 (53\%) had attended their GP surgery before going to hospital; of these three were reviewed at the A\&E/walk-in centre and sent home and two were initially seen by a community midwife (all five infants were seen $<24$ hours from onset). The remaining $7 / 15$ (47\%) infants were brought to hospital by their parents more than 24 hours from the onset of symptoms.

Overall, 20/66 (30\%) infants were assessed to have received inappropriate prehospital management. Twelve infants with fever warranted further investigation according to the NICE guidelines and, in a further eight cases, there was a delay in seeking help despite the presence of worrying clinical features. Examples of inappropriate advice given to parents included being told that their child's fever was due to a change in milk formula, or to an umbilical hernia, or where prune juice was recommended for fever and irritability.

\section{A\&E management}

Around half of the infants $(\mathrm{n}=36,55 \%)$ were triaged in A\&E during normal working hours. The median time from triage to receipt of the first antibiotic dose was 2.0 hours (IQR: $1.0-3.3$; >1 hour in 43 infants, $73 \%$ ), but was significantly shorter in infants with fever or seizures at presentation than those without these features (1.7 (IQR: $1.0-3.0$ ) vs 4.2 (IQR: $1.8-6.3$ ) hours, $\mathrm{p}=0.02$ ). There was no significant difference in median time from triage to first antibiotic dose in infants, by early-onset or late-onset disease, region of the country, time of day at presentation or whether a fluid bolus was given. The median time from onset to GP visit, hospital attendance and first dose of antibiotics varied by route taken before admission (table 3). Onset to antibiotics time was significantly longer in those who were first seen by the GP. 


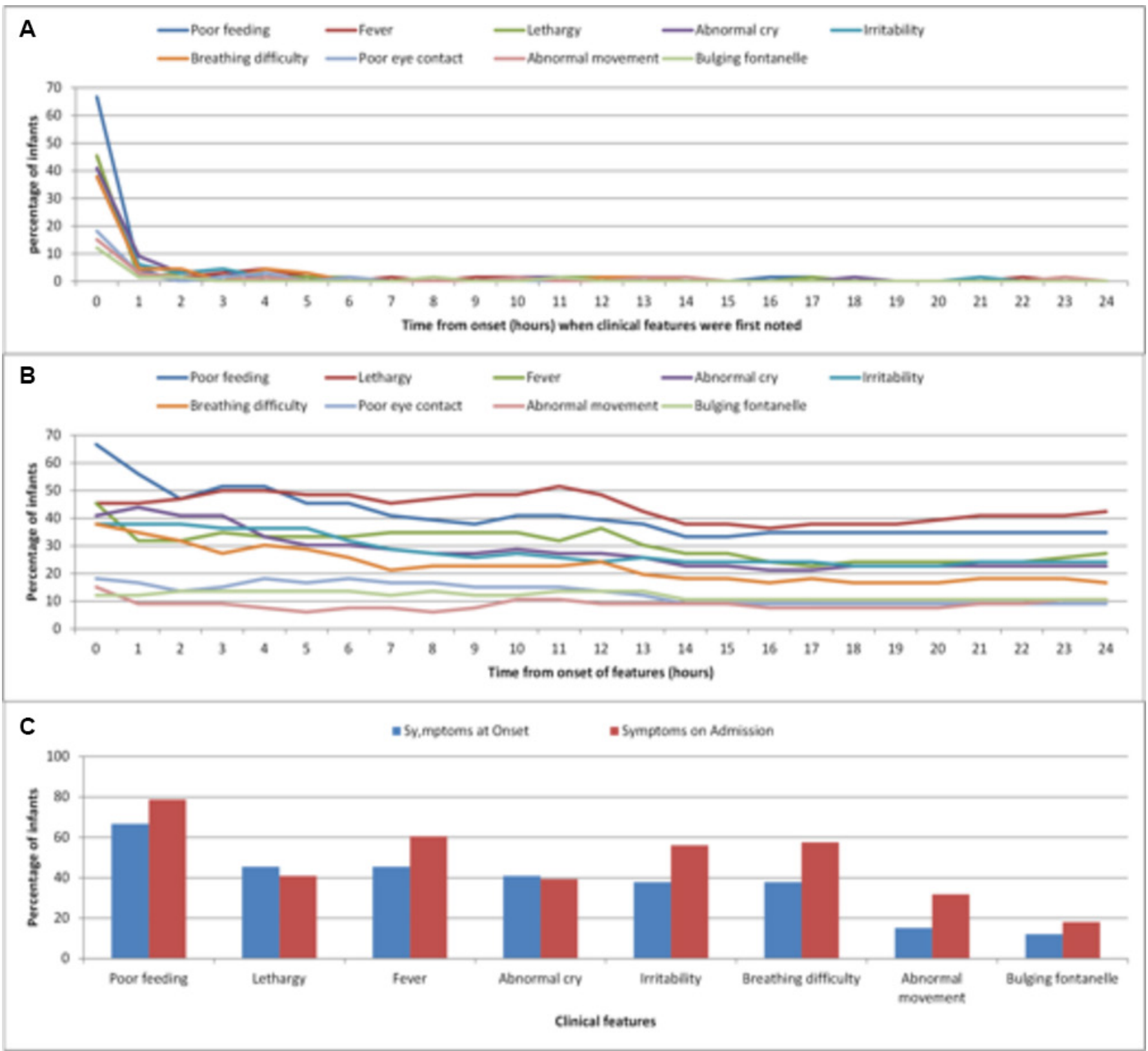

Figure 2 (A) Time (hours) at which parents first noticed a specific clinical feature. (B) Number of features present at each hour as reported by parents. (C) Clinical features present at onset and time of admission.

Overall, $26(39 \%)$ infants had a poor outcome in terms of death (one case) or neurological complication $(25,38 \%)$. These included motor disorder or developmental delay $(\mathrm{n}=12,18 \%)$, seizures $(\mathrm{n}=7,11 \%)$, hydrocephalus $(n=5,8 \%)$, hearing loss $(n=5,8 \%)$, cerebral infarct or ischaemia on MRI $(n=3,5 \%)$ or visual

Table 3 Median time in hours (IQR) from onset to general practitioner (GP), hospital visit and first dose of antibiotics by route taken prior to hospital admission

\section{Category}

Infants who went from home direct to hospital Infants who went from home to hospital via GP Infants who went to hospital via GP, were sent home and went to hospital a second time $\mathrm{p}$ Value

\section{Onset to GP}

Not applicable

10.5 hours (3-33)

9 hours (3.5-48)

0.8
Onset to hospital visit

Onset to first dose of 5.7 hours $(2-8.4)$ 11 hours $(5.2-17)$ 52 hours (36-96)

0.0001 antibiotics

8 hours $(4.8-13.5)$

13 hours (6.8-25)

57.5 hours (38-98.2) 
deficits $(n=3,5 \%)$. The median time in hours (IQR) from onset of illness to first help in infants with poor outcomes was longer than in those who recovered without sequelae (6.25 (IQR: 1-24) hours vs 4.75 (IQR: $2-10$ ) hours, $p=0.8$ ), but this was not statistically significant. The rate of poor outcome was also not statistically different between the 15 infants who were presented to hospital $>24$ hours after onset of symptoms and those who were presented $<24$ hours $(8 / 15(53 \%)$ vs $18 / 47$ $(38 \%) ; \mathrm{p}=0.3)$. The interval between triage to first antibiotic dose was also not associated with poor outcome.

A number of predefined, potential explanatory factors (age, gender, time from onset to first help, delay in antibiotics, prehospital inappropriate advice, inappropriate empiric antibiotics, presence of fever, presence of seizures) were explored in univariate and multivariate analyses to identify risk factors for poor outcome; only the presence of seizures at presentation (OR, 7.9; 95\% CI 2.3 to 207.0) was found to be an independent risk factor (see online supplementary table 1).

\section{Inpatient infants $(\mathrm{n}=\mathbf{3 1})$}

As with those infants presenting from home, parents of inpatient infants at the time of diagnosis reported that the majority of symptoms were all present at the onset of the illness (figure 3A) and remained present until diagnosis, with only a few new symptoms appearing during the course of the illness (figure 3B). The only significant difference between symptoms at onset and those at diagnosis was the proportion with breathing difficulty $(\mathrm{p}<0.001)$ (figure $3 \mathrm{C}$ ).

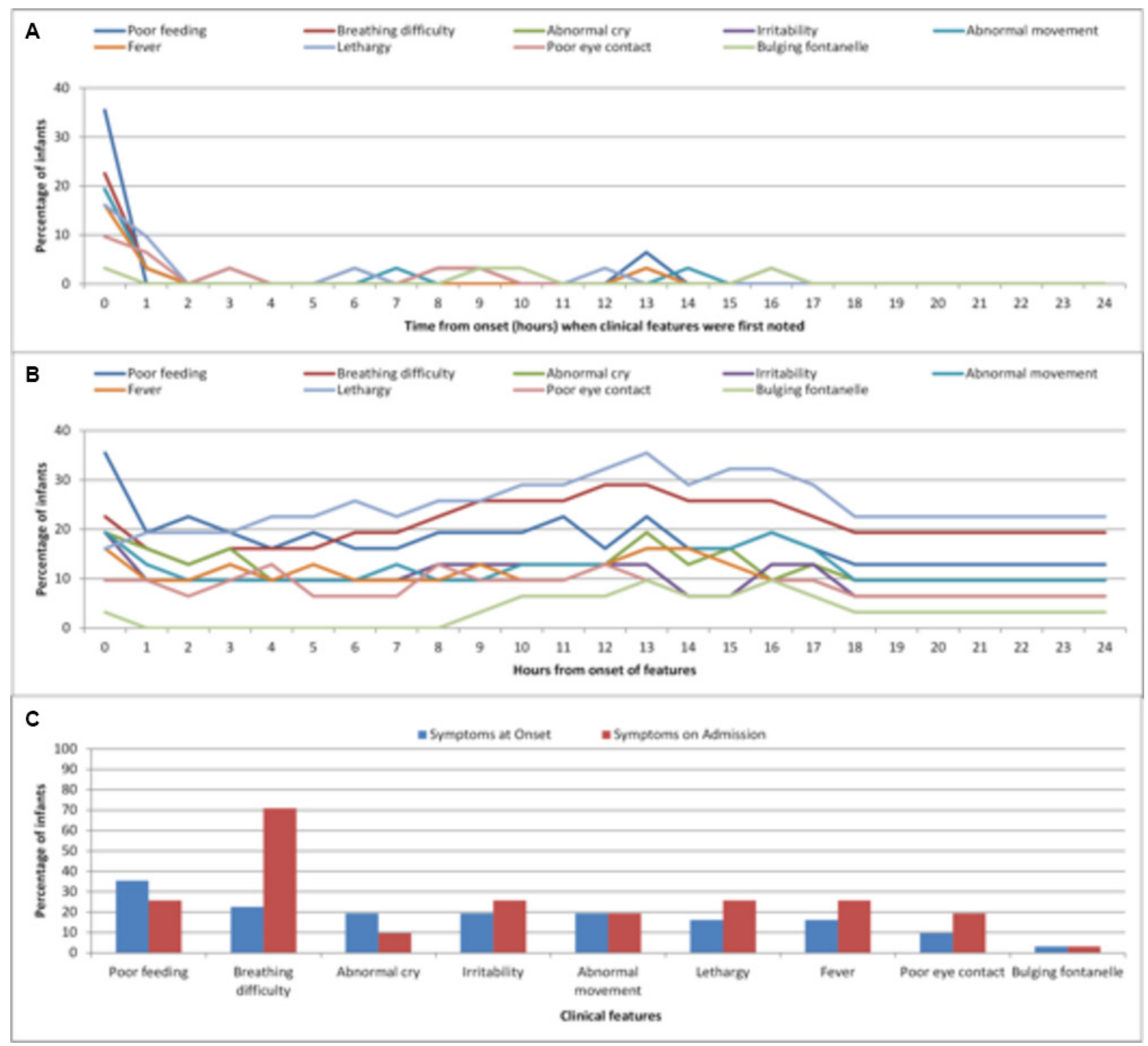

Figure 3 (A) Time (hours) at which parents first noticed a specific clinical feature (inpatient cases). (B) Number of features present at each hour as reported by parents (inpatient cases). (C) Clinical features present at onset and time of admission (inpatient cases). 
Two-thirds of infants $(21 / 31,68 \%)$ had onset of symptoms within 72 hours of birth, and were therefore assessed against the NICE early-onset antibiotic guidelines. According to these guidelines, the maternal 'red flags' (mainly chorioamnionitis/maternal sepsis in 5), baby 'red flags' (respiratory distress after 4 hours of age in 9 , shock in 4 , seizures in 2 and need for ventilation at term in 1) or both were present in 5/21 (24\%), 15/21 $(71 \%)$ and $17 / 21(81 \%)$, respectively. At the time of diagnosis, $17 / 31$ (55\%) of these infants received a fluid bolus, $12 / 31(39 \%)$ had seizures and 8/31 (26\%) had a fever.

The median time from onset of symptoms to first antibiotic dose was 2.6 hours (IQR: 1.3-8.5), with 74\% (23/31) receiving their first dose $>1$ hour after onset of symptoms and four infants $(13 \%)$ receiving the first dose $>24$ hours after onset.

\section{Outcomes among inpatient infants}

Overall, 12/31 (39\%) of infants had a serious neurological complication at hospital discharge, including developmental delay or motor disorder $(\mathrm{n}=9,29 \%)$, abnormal hearing $(\mathrm{n}=5,16 \%)$, hydrocephalus/ventriculo-peritoneal (VP) shunt $(\mathrm{n}=5,16 \%)$, seizures $(\mathrm{n}=2$, $6 \%$ ) and abnormal MRI: cortical grey and white matter injury $(n=1,3 \%)$ and two infants were treated for cerebral abscesses. No significant risk factors for poor outcomes were identified in either the univariate or multivariate analysis (see online supplementary table 1 ).

\section{Home versus inpatient infants}

The main differences between infants admitted from home and inpatient cases were age, presence of fever on presentation, timing of lumbar puncture and time to discharge from outpatient follow-up (table 4).

\section{Empiric antibiotics}

The empiric antibiotics used in 35/66 (53\%) and 17/31 $(55 \%)$ of infants admitted from home and inpatient cases, respectively, were not in conformity with the appropriate NICE guidelines (see online supplementary table 2).

\section{Follow-up and hearing tests after discharge}

The median time to first outpatient follow-up was 2.5 months (IQR: 2-3.5) and was not different among infants admitted from home and inpatient cases (table 4). However, infants from home were more likely to be discharged from follow-up before 2 years of age. A hearing test was performed in 74/96 (77\%) survivors (table 4). The median time from discharge to hearing test was 25 days (IQR: 0-32), with $30(41 \%)$ and $14(19 \%)$ infants having the hearing test $\geq 4$ and $\geq 6$ weeks after hospital discharge, respectively.

Table 4 Comparison of infants admitted from home and infants in hospital at the time of diagnosis

\begin{tabular}{|c|c|c|c|c|}
\hline Variable & All cases & Home $(n=66)$ & Inpatient $(n=31)$ & p Value \\
\hline Median age at disease (days) & $14(3-25)$ & $17(11-34)$ & $1(0-7)$ & 0.0001 \\
\hline Early onset (<7 days) & $30(31 \%)$ & $8(12 \%)$ & $22(71 \%)$ & $<0.0001$ \\
\hline Prematurity & $23(24 \%)$ & $8(12 \%)$ & $15(48 \%)$ & $<0.0001$ \\
\hline Out-of-hours presentation & $47(48 \%)$ & $30(45 \%)$ & $17(55 \%)$ & 0.4 \\
\hline Seizure at presentation & $33(34 \%)$ & $21(32 \%)$ & $12(39 \%)$ & 0.5 \\
\hline Received fluid bolus at presentation & $53(55 \%)$ & $36(55 \%)$ & 17 (55\%) & 0.7 \\
\hline Antibiotics delay (hours) & $2(1.3-4)$ & $2(1-3.3)$ & $2.6(1.3-9.8)$ & 0.09 \\
\hline LP done post first dose of antibiotics & 57 (59\%) & $30(45 \%)$ & $27(87 \%)$ & $<0.0001$ \\
\hline Antibiotics to LP time $>24$ hours & $33(59 \%)$ & $14(47 \%)$ & $19(70 \%)$ & 0.07 \\
\hline Empiric antibiotics not in conformity with national guidelines & $52(54 \%)$ & $35(53 \%)$ & $17(55 \%)$ & 0.9 \\
\hline Discharge to first OPD review (months) & $2.5(2.0-3.5)$ & $2.5(2.0-4.0)$ & $2.5(2.0-2.5)$ & 0.6 \\
\hline Discharge from follow-up age $<12$ months & $13(14 \%)$ & $12 / 65(18 \%)$ & $1 / 31(3 \%)$ & 0.03 \\
\hline Discharge from follow-up age $<24$ months & $31(32 \%)$ & $26 / 65(40 \%)$ & $5 / 31(16 \%)$ & 0.02 \\
\hline Hearing test performed in survivors* & $74(77 \%)$ & $53 / 65(82 \%)$ & $21 / 31(68 \%)$ & 0.1 \\
\hline Neurological complications & $40(42 \%)$ & $26 / 65(40 \%)$ & $14 / 31(45 \%)$ & 0.6 \\
\hline Discharge to audiology test (days) & $25(0-32)$ & $24(10-42)$ & $26(0-28)$ & 0.2 \\
\hline Informed of meningitis support charities & $13 / 97(13 \%)$ & $11 / 66(17 \%)$ & 2/31 (6\%) & 0.2 \\
\hline
\end{tabular}

*There were 22 survivors without report of hearing test. 12 (13\%) had no record of hearing test at review, $5(5 \%)$ were transferred to another hospital where data were not available, and $4(12 \%)$ had the review $<1$ month after discharge and $1(1 \%)$ missed two appointments.

CSF, cerebrospinal fluid; LP, lumbar puncture; OPD, outpatient department. 


\section{DISCUSSION}

This is the first study to assess in detail the course of the illness in young infants with bacterial meningitis and the early healthcare they receive. Parental reporting of the early features of bacterial meningitis is a unique aspect of this study. We have shown that in infants with bacterial meningitis, most of the symptoms and signs as reported by parents are present from the onset of the illness and there is little progression, with no or few additional symptoms developing as the illness progresses. Notably, up to $40 \%$ of infants did not develop fever at any time during their illness. In keeping with previous studies, only seizures at presentation were significantly associated with a poor outcome. ${ }^{2}$

The course of bacterial meningitis in young infants appears to be different from that of children with meningococcal meningitis. With a similar study design, Thompson and colleagues demonstrated that meningococcal disease progresses in a stereotypical manner in all children, with a prodromal phase, early sepsis phase and meningism only as a late feature. ${ }^{6}$ In terms of the healthcare-seeking behaviour for those infants admitted from home, $70 \%$ of parents had sought medical help prior to A\&E attendance. Of concern, a significant proportion had received inappropriate advice, suggesting that further training of front-line healthcare staff in recognising serious illness in children is required. ${ }^{18}$ On the other hand, many of the parents who presented to hospital more than 24 hours after the initial healthcare contact are most likely because their child's condition deteriorated, thus highlighting the importance of providing appropriate safety-netting advice to parents if they are advised to return home.

On admission to hospital, the median time from triage to first antibiotic dose was 2 hours, lower than that recently reported for childhood septicaemia (3 hours) ${ }^{19}$ but higher than the recommended threshold of 1 hour. ${ }^{20}$ We identified a number of reasons for this delay, including uncertainty in recognition (especially in those with non-specific presentations), over-reliance on the presence of fever, waiting for urine samples before giving antibiotics and waiting for handover between shifts. Presentation in-hours or out-of-hours did not influence time to first antibiotic, which is reassuring given that half of infants were presented out of hours. That infants with fever or seizure received antibiotics more quickly than those without these features suggests that these delays can potentially be avoided. Miner $e t$ al showed that delay to antibiotics time is significantly shorter in patients who received it in the emergency department. ${ }^{21}$ With appropriate education strategies, it is therefore possible to significantly improve antibiotic delivery time for infants. ${ }^{22}$

Most inpatient infants developed meningitis within 72 hours of birth, suggesting vertical transmission of infection. The recent NICE guidelines for early-onset antibiotics provide guidance on maternal, birth and infant risk factors that should lead to specific and timely antibiotic therapy. ${ }^{17}$ Notably, $80 \%$ of infants had such risk factors, suggesting this to be a useful tool. However the time to antibiotic administration and the choice of antibiotic were still very variable. Adult studies from USA and France reported low compliance to established guidelines. ${ }^{23} 24$

There is still a need to reinforce to clinicians the importance of performing a timely hearing test in infants with bacterial meningitis. There is no record of such a test in $23 \%$ of cases, and even when done it was $\geq 4$ weeks in $40 \%$. National guidelines emphasise the need for early diagnosis of deafness to allow early interventions such as cochlear implantation. ${ }^{16}$ Follow-up of infants with bacterial meningitis is also believed to be important as it should allow early identification of those with neurodevelopmental impairment (likely to be around $50 \%$ of survivors $)^{425}$ and timely intervention and support. ${ }^{16}$

\section{SUMMARY}

The impact of bacterial meningitis on young infants and their families is significant. Case fatality rates and severe complications among survivors remain unacceptably high, at least partly due to delayed recognition and management. Unlike children with meningococcal disease, for example, we were unable to identify any distinctive features at disease onset or of symptom progression that might aid earlier recognition or trigger earlier healthcare presentation. We propose a targeted campaign for education of new parents, primary care health workers (including telephone advice providers) and hospital doctors regarding the non-specific features, the lack of progression of clinical features at least in the first 24 hours and the lack of fever in young infants with bacterial meningitis. There is also need to explore ways of harmonising clinical practice with evidence-based management algorithms, including timely investigation and administration of appropriate antibiotics and adequate follow-up of infants with bacterial meningitis.

Acknowledgements We acknowledge the meningitis support charities (Meningitis Research Foundation, Meningitis Now formerly Meningitis Trust and Meningitis UK) and the Group B Strep Support charity for their help with reports from parents. We are grateful to Professor Alan P Johnson, who co-conceived and designed the study including the grant application and led the LabBase data collection at the Public Health England, and his colleagues Katherine L Henderson, Ruth M Blackburn and Berit Muller-Pebody, who coordinated the laboratory reporting via LabBase. We also wish to acknowledge the local paediatricians who were participant identification centre (PIC) contacts.

Contributors 100 completed the ethics application form, finalised the data collection tool, coordinated the study, entered all data into an Access database, data interpretation, performed the analysis, wrote the initial manuscript, reviewed and revised the manuscript, and submitted the final manuscript. SNL helped with case ascertainment from the Public Health England, supported the data analysis and data interpretation, reviewed and revised the manuscript, and approved the final manuscript. MA co-conceived and designed the study, including the grant application, was a member of the expert panel who reviewed the management of cases, took part in data interpretation, reviewed and revised the manuscript, and approved the final manuscript. NN co-conceived and designed the study, including the grant application, was a member of the expert panel who reviewed the management of cases, took part in data interpretation, reviewed and revised the manuscript, and approved the final manuscript. PTH was the chief investigator, coconceived and designed the study, including the grant and ethics application, was 
a member of the expert panel who reviewed the management of cases, contributed to the data analysis and data interpretation, reviewed and revised the manuscript, and approved the final manuscript.

Funding The Meningitis Research Foundation funded the study, and initial data collection and analysis. The funding body did not influence study design, data collection, data analysis, data interpretation, writing of the report or the decision to submit the paper for publication. The corresponding author had full access to all the data in the study and had final responsibility for the decision to submit for publication.

Competing interests All authors have completed the ICMJE uniform disclosure form at www.icmje.org/coi_disclosure.pdf and declare no support from any organisation for the submitted work. PTH is a consultant for Novartis and Pfizer on group B streptococcus vaccines but receives no payment for this. NN is a consultant for Pfizer on meningococcal group B vaccines, and has received honoraria to teaching on meningitis from Novartis. All other authors declare no conflicts of interests. The ICMJE form for disclosure of potential conflicts of interest has been submitted.

Ethics approval Ethical approval was given by Cambridgeshire 2 REC (Ref: 10/ H0308/64). Paediatricians were approached by email asking if they would be willing to take part in the study. If in agreement, a National Institute for Health Research Coordinated System for gaining NHS Permission (NIHR CSP) application was made and the hospital listed once approval was granted.

Provenance and peer review Not commissioned; externally peer reviewed.

Data sharing statement Extra data can be accessed via the Dryad data repository at http://datadryad.org/ with the doi:10.5061/dryad.601m8.

Open Access This is an Open Access article distributed in accordance with the Creative Commons Attribution Non Commercial (CC BY-NC 4.0) license, which permits others to distribute, remix, adapt, build upon this work non-commercially, and license their derivative works on different terms, provided the original work is properly cited and the use is non-commercial. See: http://creativecommons.org/ licenses/by-nc/4.0/

(c) Article author(s) (or their employer(s) unless otherwise stated in the text of the article) 2017. All rights reserved. No commercial use is permitted unless otherwise expressly granted.

\section{REFERENCES}

1. Okike IO, Johnson AP, Henderson $\mathrm{KL}$, et al. Incidence, etiology, and outcome of bacterial meningitis in infants aged $<90$ days in the United kingdom and republic of Ireland: prospective, enhanced, national population-based surveillance. Clin Infect Dis 2014;59:e150-7.

2. Okike IO, Ladhani SN, Johnson AP, et al. Clinical characteristics and risk factors for poor outcomes in infants aged $<90$ days with bacterial meningitis in UK and Ireland. Pediatr Infect Dis J 2017. In Press.

3. Bedford $\mathrm{H}$, de Louvois $\mathrm{J}$, Halket $\mathrm{S}$, et al. Meningitis in infancy in England and Wales: follow up at age 5 years. BMJ 2001;323:533-6.

4. de Louvois J, Halket S, Harvey D. Neonatal meningitis in England and Wales: sequelae at 5 years of age. Eur J Pediatr 2005;164:730-4.

5. Okike IO, Ribeiro S, Ramsay ME, et al. Trends in bacterial, mycobacterial, and fungal meningitis in England and Wales 2004-11: an observational study. Lancet Infect Dis 2014;14:301-7.
6. Thompson MJ, Ninis N, Perera R, et al. Clinical recognition of meningococcal disease in children and adolescents. Lancet 2006;367:397-403.

7. Booy R, Habibi P, Nadel S, et al. Reduction in case fatality rate from meningococcal disease associated with improved healthcare delivery. Arch Dis Child 2001;85:386-90.

8. Carcillo JA, Davis AL, Zaritsky A. Role of early fluid resuscitation in pediatric septic shock. JAMA 1991;266:1242-5.

9. Han YY, Carcillo JA, Dragotta MA, et al. Early reversal of pediatricneonatal septic shock by community physicians is associated with improved outcome. Pediatrics 2003;112:793-9.

10. Proulx N, Fréchette D, Toye B, et al. Delays in the administration of antibiotics are associated with mortality from adult acute bacterial meningitis. QJM 2005;98:291-8.

11. Garges HP, Moody MA, Cotten CM, et al. Neonatal meningitis: what is the correlation among cerebrospinal fluid cultures, blood cultures, and cerebrospinal fluid parameters? Pediatrics 2006;117:1094-100.

12. Kestenbaum LA, Ebberson J, Zorc JJ, et al. Defining cerebrospinal fluid white blood cell count reference values in neonates and young infants. Pediatrics 2010;125:257-64.

13. Greenberg RG, Smith PB, Cotten CM, et al. Traumatic lumbar punctures in neonates: test performance of the cerebrospinal fluid white blood cell count. Pediatr Infect Dis J 2008;27:1047-51.

14. Pearson A, Chronias A, Murray M. Voluntary and mandatory surveillance for methicillin-resistant Staphylococcus aureus (MRSA) and methicillin-susceptible S. aureus (MSSA) bacteraemia in England. J Antimicrob Chemother 2009;64(Suppl 1):i11-17.

15. NICE. Feverish illness in children: assessment and initial management in children younger than 5 years. http://guidance.nice. org.uk/CG47/QuickRefGuide/pdf/English (accessed 06 Sep 2016).

16. NICE. Bacterial meningitis and meningococcal septicaemia: management of bacterial meningitis and meningococcal septicaemia in children and young people younger than 16 years in primary and secondary care. http://guidance.nice.org.uk/CG102 (accessed 6 Sep 2016).

17. NICE. Neonatal infection (early onset): antibiotics for prevention and treatment. https://www.nice.org.uk/guidance/CG149 (accessed 06 Sep 2016).

18. Pearson GA (Ed). Why Children Die: A Pilot Study 2006; England (SouthWest, North East and West Midlands), Wales and Northern Ireland. London: CEMACH, 2008.

19. Irwin AD, Drew RJ, Marshall $P$, et al. Etiology of childhood bacteremia and timely antibiotics administration in the emergency department. Pediatrics 2015;135:635-42.

20. Chaudhuri A, Martinez-Martin P, Martin PM, et al. EFNS guideline on the management of community-acquired bacterial meningitis: report of an EFNS Task Force on acute bacterial meningitis in older children and adults. Eur J Neurol 2008;15:649-59.

21. Miner JR, Heegaard W, Mapes A, et al. Presentation, time to antibiotics, and mortality of patients with bacterial meningitis at an urban county medical center. J Emerg Med 2001;21:387-92.

22. Bissinger RL, Mueller M, Cox TH, et al. Antibiotic timing in neonates with suspected hospital-acquired infections. Adv Neonatal Care 2013;13:22-8. quiz 29-30.

23. Chia D, Yavari Y, Kirsanov E, et al. Adherence to standard of care in the diagnosis and treatment of suspected bacterial meningitis. Am J Med Qual 2015;30:539-42.

24. Georges H, Chiche A, Alfandari S, et al. Adult community-acquired bacterial meningitis requiring ICU admission: epidemiological data, prognosis factors and adherence to IDSA guidelines. Eur J Clin Microbiol Infect Dis 2009;28:1317-25.

25. Stevens JP, Eames M, Kent A, et al. Long term outcome of neonatal meningitis. Arch Dis Child Fetal Neonatal Ed 2003;88:F179-84. 